\title{
Experimental Forecasts of the Indian Ocean Dipole Using a Coupled OAGCM
}

\author{
JING-JIA LUO \\ Frontier Research Center for Global Change, JAMSTEC, Yokohama, Japan \\ Sebastien Masson \\ LOCEAN/IPSL, Université Pierre et Marie Curie, Paris, France \\ Swadhin BeHERA AND Toshio Yamagata* \\ Frontier Research Center for Global Change, JAMSTEC, Yokohama, Japan
}

(Manuscript received 7 April 2006, in final form 25 September 2006)

\begin{abstract}
The Indian Ocean Dipole (IOD) has profound socioeconomic impacts on not only the countries surrounding the Indian Ocean but also various parts of the world. A forecast system is developed based on a relatively high-resolution coupled ocean-atmosphere GCM with only sea surface temperature (SST) information assimilated. Retrospective ensemble forecasts of the IOD index for the past two decades show skillful scores with up to a 3-4-month lead and a winter prediction barrier associated with its intrinsic strong seasonal phase locking. Prediction skills of the SST anomalies in both the eastern and western Indian Ocean are higher than those of the IOD index; this is because of the influences of ENSO, which is highly predictable. The model predicts the extreme positive IOD event in 1994 at a $2-3$-season lead. The strong 1997 cold signal in the eastern pole, however, is not well predicted owing to errors in model initial subsurface conditions. The real-time forecast system with more ensembles successfully predicted the weak negative IOD event in the 2005 boreal fall and La Niña condition in the 2005/06 winter. Recent experimental real-time forecasts showed that a positive IOD event would appear in the 2006 summer and fall accompanied by a possible weak El Niño condition in the equatorial Pacific.
\end{abstract}

\section{Introduction}

Ocean-atmosphere coupled dynamics play an active role in the tropical Indian Ocean climate variability. The Indian Ocean Dipole (IOD) is a synthesis of such positive feedback processes among the zonal sea surface temperature (SST) contrast, surface wind, and oceanic thermocline tilt (e.g., Saji et al. 1999; Webster et al. 1999). During extreme positive IOD years such as 1994 and 1997, the thermocline along the west coast of Sumatra shallows because of anomalous alongshore

\footnotetext{
* Additional affiliation: Department of Earth and Planetary Science, University of Tokyo, Tokyo, Japan.
}

Corresponding author address: Jing-Jia Luo, Frontier Research Center for Global Change, JAMSTEC, 3173-25 Showa-machi, Kanazawa-ku, Yokohama, Kanagawa 236-0001, Japan.

E-mail: luo@jamstec.go.jp southeasterly winds. SST west of Sumatra strongly cools because of the anomalous upwelling and evaporation, and warmer SST tends to appear in the western Indian Ocean (WIO). Corresponding to this zonal SST anomaly pattern, severe drought tends to happen in the eastern Indian Ocean (EIO), Indonesia, and Australia; torrential rains are observed in the western Indian Ocean and eastern Africa (Birkett et al. 1999; Ansell et al. 2000; Clark et al. 2003; Behera et al. 2005). Anomalously strong convective activities associated with IOD episodes may trigger planetary atmospheric waves, which carry IOD influences to far distant regions (e.g., Saji and Yamagata 2003).

Because of the ocean-atmosphere coupled dynamics, potential predictability of El Niño-Southern Oscillation (ENSO) events was expected during the Tropical Ocean Global Atmosphere (TOGA) period. Learning from the success of the ENSO forecast and its societal benefit (e.g., Cane et al. 1986; Stockdale et al. 1998), the possible warning of an impending IOD episode at a few

DOI: 10.1175/JCLI4132.1

(C) 2007 American Meteorological Society 
seasons lead could greatly reduce socioeconomic losses, especially in the Indian Ocean rim countries. Compared to the predictions of ENSO events, however, larger difficulties exist for IOD predictions. This is because the Indian Ocean climate is affected by more complicated physical processes such as the strong Indian/Asian monsoon, external influences of ENSO, and chaotic intraseasonal oscillations (ISOs) in both the atmosphere and ocean (e.g., Rao and Yamagata 2004; Masumoto et al. 2005; Han et al. 2006). Current oceanatmosphere coupled models for IOD forecasts still suffer from their large deficiencies in correctly simulating the Indian Ocean climate (e.g., Gualdi et al. 2003; Yamagata et al. 2004; Wajsowicz 2004; Cai et al. 2005). Besides, large errors exist in the initial conditions for IOD forecasts because of the very sparse observations in the Indian Ocean. Despite those, efforts made so far have shown that predicting IOD events up to one or two seasons ahead is promising (Luo et al. 2005b; Wajsowicz 2005).

In this study, we evaluate the IOD predictability and its seasonal dependence based on an advanced oceanatmosphere coupled general circulation model (GCM) with only SST data assimilated. A special emphasis is put on the predictability of extreme IOD events that may cause severe climate impacts in various regions of the globe. Influences of errors in the model and initial conditions on the IOD predictability are also investigated. The results may help to assess the potential importance of a long-term observation system in the tropical Indian Ocean and the capability of current state-ofthe-art coupled GCMs in predicting the climate variations there. The coupled model and hindcast experiments are described in section 2. Model hindcast results over the past 2 decades and real-time forecasts for 2005-06 are shown in sections 3 and 4. A summary and discussion is given in section 5 .

\section{Methods}

The global ocean-atmosphere coupled GCM used in this study, called SINTEX-F (e.g., Luo et al. 2003, 2005a), was developed under the (European Union) EU-Japan collaboration. The atmospheric component has the resolution of $1.1^{\circ}$ (T106) with 19 vertical levels. The oceanic component has the resolution of a $2^{\circ} \mathrm{Mer}-$ cator mesh (increased to $0.5^{\circ}$ in the latitudinal direction near the equator) with 31 vertical levels. Those two components are coupled directly without flux corrections. The SINTEX-F model realistically simulates both ENSO and IOD variabilities, including their magnitudes, periods, and the spatial distribution of SST anomalies in the Indo-Pacific region (Yamagata et al. 2004; Luo et al. 2005a; Behera et al. 2005). a) $\operatorname{SST}\left({ }^{\circ} \mathrm{C}\right)$

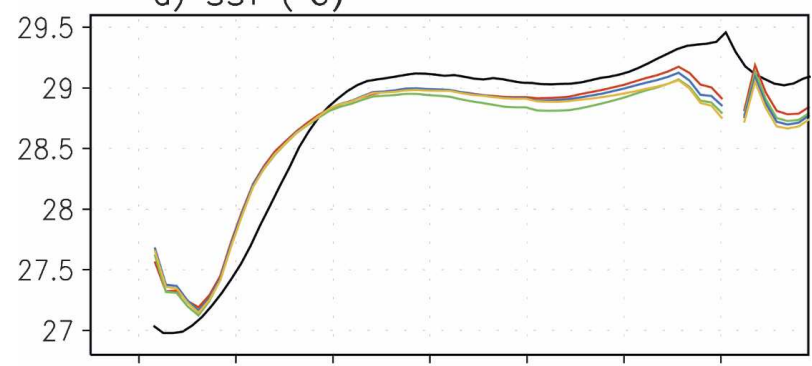

b) $\mathrm{U} 10 \mathrm{~m}\left(\mathrm{~ms}^{-1}\right)$

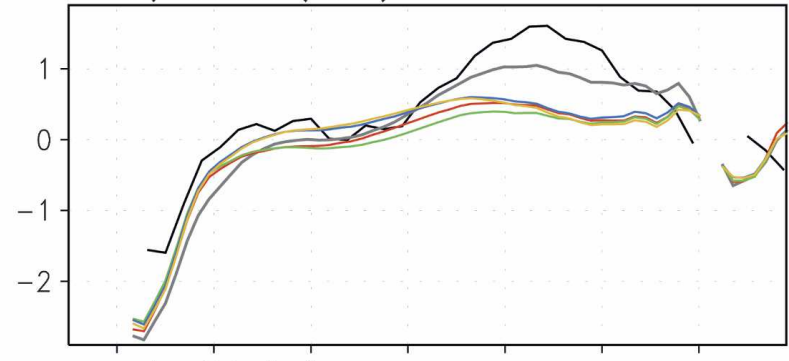

c) $d 20(m)$

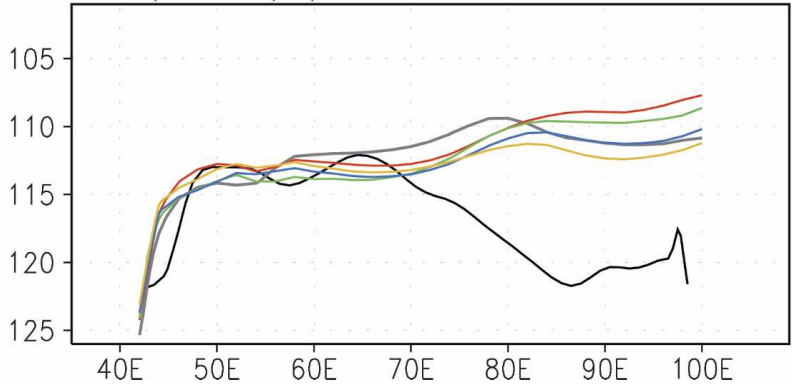

FIG. 1. (a) Annual mean SST climatology for the period of $1983-2004$ in the equatorial Indian Ocean $\left(2^{\circ} \mathrm{S}-2^{\circ} \mathrm{N}\right)$ based on the NCEP observations (black line) and 9-member mean forecasts at 3-, 6-, 9-, and 12-month leads (red, green, blue, and yellow lines). (b) Same as in (a), but for the surface zonal winds at 10-m height. Gray line denotes nine-member mean values produced by the coupled SST nudging scheme. (c) Same as in (b), but for the $20^{\circ} \mathrm{C}$ isotherm depth. Black line denotes the World Ocean Atlas 2001 observations Stephens et al. (2002).

We have performed nine-member ensemble retrospective forecasts for the period of 1982-2004. Uncertainties for seasonal forecasts are originated not only in the initial conditions but also in the model physics. Because of the large uncertainties in surface wind stress estimations and the importance of strong ocean surface currents in the Tropics, we perturb the model coupling physics in three different ways (Luo et al. 2005a). Three different initial conditions for each model are generated by a coupled SST nudging scheme with three large negative heat flux feedback values (Luo et al. 2005b). They correspond to 1-, 2-, and 3-day restoring time for temperature in a 50-m mixed layer. Such an initialization approach (without subsurface information assimilated) requires a good model performance in simulating 

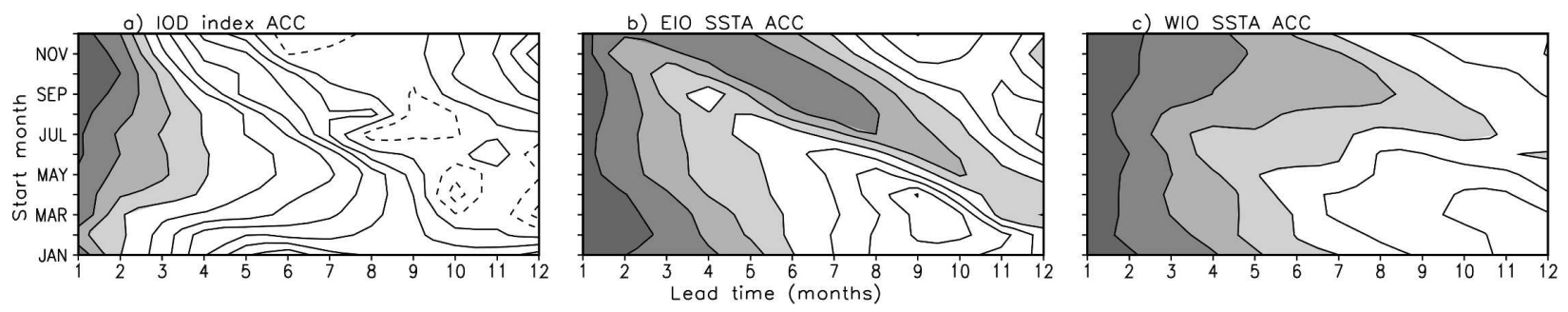

FIG. 2. Seasonally stratified anomaly correlation coefficients (ACCs) between the observations and model predictions during 19822004 for (a) the IOD index, (b) SST anomalies in the eastern pole (EIO; $10^{\circ} \mathrm{S}-0^{\circ}, 90^{\circ}-110^{\circ} \mathrm{E}$ ), and (c) the western pole (WIO; $10^{\circ} \mathrm{S}-10^{\circ} \mathrm{N}, 50^{\circ}-70^{\circ} \mathrm{E}$ ). Contour interval is 0.1 and regions with values above 0.6 are shaded. The IOD index is defined as the SST anomaly difference between the western and eastern pole. Skills are calculated based on the time series of 5-month running means of both the observations and model hindcasts at each lead time. This tends to give proper estimates of the predictability of climate variations beyond the intraseasonal time scale (Luo et al. 2005b).

the tropical climate. It could provide compatible initial conditions between the atmosphere and ocean, and therefore, reduce the initial shock during forecasts (e.g., Chen et al. 1995). SST used for the initialization is from the National Centers for Environmental Prediction (NCEP) weekly optimum interpolation (OI) analysis available from January 1982 (see online at http:// www.cdc.noaa.gov/). The weekly data have been interpolated into a daily mean using a cubic spline method. The nine-member ensemble hindcasts with lead times up to 12 months are made from the first day of each month during the period of 1982-2004. We note that the prediction skills of the global SST anomalies based on the nine members are similar to those based on the previous five members (Luo et al. 2005b) except with a slight improvement in the tropical Indian Ocean (not shown).

Over the 12-month forecast period, model SST drifts in the equatorial Pacific are less than $1^{\circ} \mathrm{C}$ (Luo et al. 2005b, 2006, manuscript submitted to J. Climate). ENSO events over the past 2 decades could be skillfully predicted at up to a 12-month lead (Luo et al. 2005b). In the equatorial Indian Ocean, SST drifts are small, only about $0.2^{\circ} \mathrm{C}$ cooler (warmer) in the eastern (western) part than the NCEP observations (Fig. 1a). The climatological mean zonal SST gradient between the west and the east is captured reasonably well. Forced by observed SSTs, the atmospheric GCM produces realistic surface zonal winds but with weaker westerlies in the east compared to the NCEP-NCAR reanalysis (see gray and black lines in Fig. 1b). This might be one of the reasons why the model thermocline in the east is too shallow (Fig. 1c). ${ }^{1}$ The shallow thermocline there favors a strong coupling between the SST and thermocline; this may cause the IOD-related SST anomaly to extend too far west (e.g., Yamagata et al. 2004). It is interesting

\footnotetext{
${ }^{1}$ We note that the equatorial thermocline is simulated better in the coupled model with wind stress corrections.
}

that the thermocline in the east does not rise farther up during the 12-month forecast period despite the weakened surface westerlies there (see colored lines in Figs. $1 b, c)$. Further efforts are needed to minimize the drifts of both the SST and thermocline in the equatorial Indian Ocean; this is crucial to avoiding a rapid decline of skill in IOD predictions. We note that the model climate drifts have been removed a posteriori from each member prior to calculating the ensemble mean anomaly and prediction skill (see also Kirtman et al. 1997; Stockdale 1997).

\section{Retrospective forecasts}

\section{a. Overall assessment}

Figure 2 shows nine-member ensemble mean prediction skills of the IOD index and SST anomalies in the eastern and western poles over the past 2 decades. The model shows a rapid drop of skill in IOD predictions across boreal winter (Fig. 2a), which is consistent with the rapid decrease of its observed persistence during the same season (e.g., Saji et al. 1999). This is distinct from the well-known spring barrier of ENSO. The unique winter barrier reflects the strong seasonal phase locking of IOD. It develops in summer and peaks in fall under the positive air-sea feedback (e.g., Saji et al. 1999). The signal after reaching its height then collapses quickly in winter, owing to the reversal of monsoonal winds (e.g., Li et al. 2003). Consistent with the winter barrier of IOD, predictions of the SST anomalies in the eastern pole also show minimum skills in winter (Fig. 2b). The skills, however, rebound in late winter/early spring and then decline again in late spring; this latter barrier is related to ENSO influences (Luo et al. 2005b). SST anomalies in the western pole are more predictable but with a spring barrier because of stronger influences of ENSO there (Fig. 2c). The results are similar and comparable to those obtained by other forecast systems (e.g., Wajsowicz 2004, 2005). 


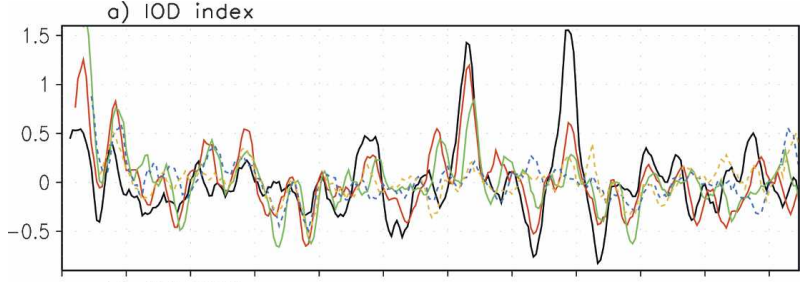

b) EIO SSTA

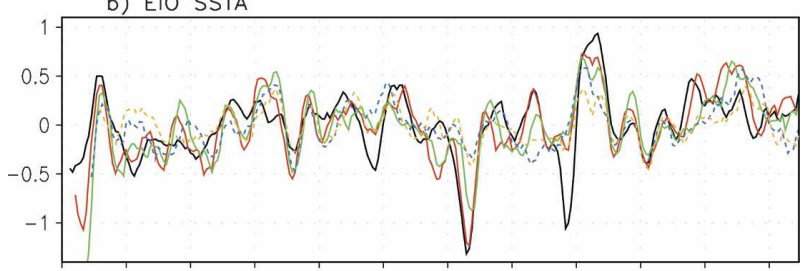

c) WIO SSTA

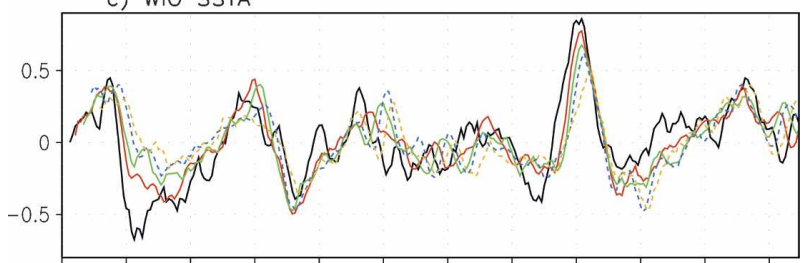

d) Ueq anom

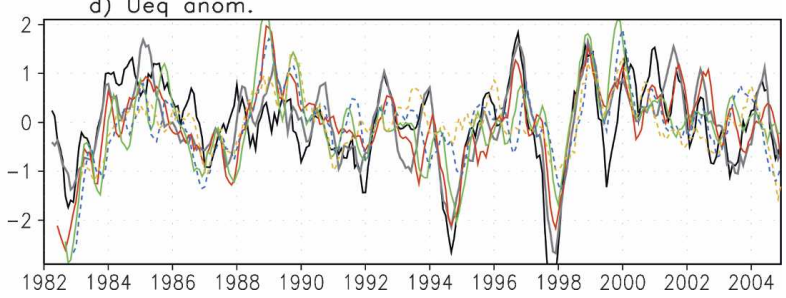

FIG. 3. The (a) IOD index, (b) EIO and (c) WIO SST anomalies, and (d) surface zonal wind anomaly in the central equatorial Indian Ocean $\left(U_{\text {eq }} ; 5^{\circ} \mathrm{S}-5^{\circ} \mathrm{N}, 70^{\circ}-90^{\circ} \mathrm{E}\right)$ based on the NCEP observations (black lines) and model predictions at 3-, 6-, 9-, and 12-month leads (red, green, blue, and yellow lines). Results have been smoothed with a 5-month running mean. We note that, despite the model weak climatology, interannual $U_{\text {eq }}$ variations produced by the coupled SST nudging scheme (see gray line in d) are similar to the NCEP-NCAR reanalysis.

Interannual ENSO episodes may have significant impacts on the development of IOD in some cases, as in 1997 (Webster et al. 1999), and vice versa (Behera and Yamagata 2003). Figure 3 shows the IOD index, SST anomalies in the eastern and western poles, and zonal surface wind anomalies in the central equatorial Indian Ocean from the observations and model predictions at 3-, 6-, 9-, and 12-month leads. The strong warm SST anomalies in the western Indian Ocean in 1997/98 are well predicted up to a 12-month lead except that the predicted onset is slightly delayed (Fig. 3c; see also Wajsowicz 2005). Besides, the warm signals during other years (1983, 1987, 1991, and 2003) and cold ones $(1985,1989,1996$, and 1999) in the western pole are predicted reasonably well up to a 9-12-month lead. This is associated with ENSO influences. SSTs in the eastern pole in late 1997 are predicted to be colder than normal up to a 12-month lead but the predicted magnitudes are much weaker than the observed (Fig. 3b). Correspondingly, the predicted IOD index in 1997 is weak (Fig. 3a). The easterly wind anomalies in the central Indian Ocean, however, are well predicted even at a 9-12-month lead associated with the strongest 1997/98 El Niño event (Fig. 3d).

Long-term mean state changes in the tropical IndoPacific Ocean may also modulate the frequency and magnitude of IOD under some circumstances (e.g., Tozuka et al. 2007). Decadal El Niño-like conditions in the Pacific tend to induce an anomalous atmospheric anticyclone in the south Indian Ocean that slackens the annual mean surface westerly winds along the equator, and hence, flattens the equatorial thermocline (e.g., Luo et al. 2003; Tozuka et al. 2007). The rise of the thermocline in the east, especially along the Sumatra, could favor the occurrence of extreme positive IOD, as observed in 1994 and simulated in several oceanatmosphere coupled GCMs (Behera et al. 1999; Gualdi et al. 2003; Yamagata et al. 2004; Wajsowicz 2004; Cai et al. 2005). The strong positive IOD index, cold SST anomalies in the eastern pole, and surface easterly anomalies in the central region in 1994 are well predicted by the model at a 6-month lead (Fig. 3). We note that the model gives skillful predictions $(\geq 0.6)$ for the IOD index and SST anomalies in the eastern and western poles up to 3-, 5-, and 7-month leads, respectively, with root-mean-square errors less than $0.2^{\circ}-0.3^{\circ} \mathrm{C}$ and a small number of false alarms at these lead times. ${ }^{2}$

\section{b. Case studies of 1994 and 1997}

\section{1) Prediction Plumes}

Figure 4 shows the model prediction plumes of the SST anomalies in the two poles of IOD and in the Niño-3.4 region during the two extreme positive IOD events of 1994 and 1997. The cold SST anomalies in the eastern pole during both events can be predicted from the previous fall and winter but with much weakened magnitudes (Fig. 4a). The evolution of the strong cold SST anomaly in 1994 (i.e., growth in May-July, peak in August-October, and rapid demise in NovemberDecember 1994) is realistically predicted from the spring of 1994. However, the model fails to predict the 1997 case. This is partly due to the influence of a warm ISO event in the 1997 spring; forecasts initiated from 1 May 1997 even give a false alarm of a warm condition

\footnotetext{
${ }^{2}$ Skill scores are reduced by $0.1-0.2$ if ISOs are taken into account for calculations. Skillful predictions of the 3 unfiltered indices can be made only at 2-, 3-, and 4-month leads, respectively.
} 
a) EIO SSTA

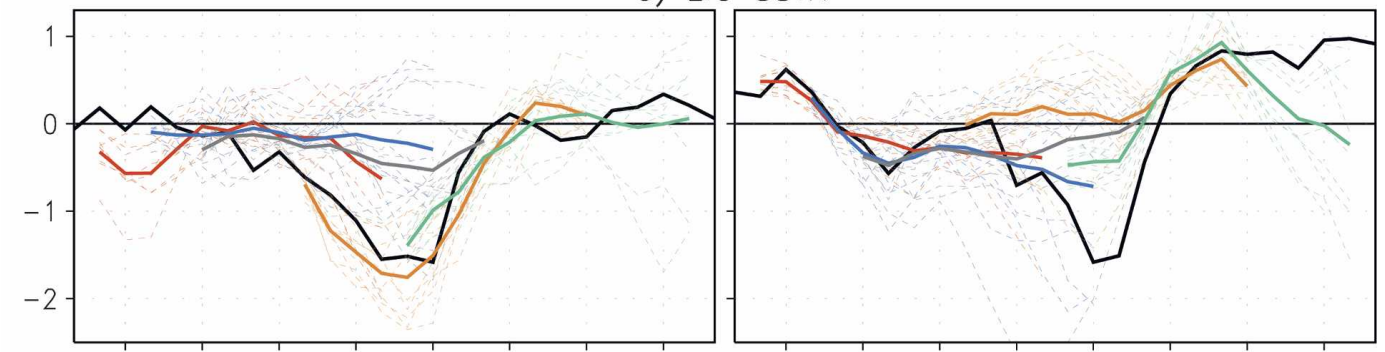

b) WIO SSTA

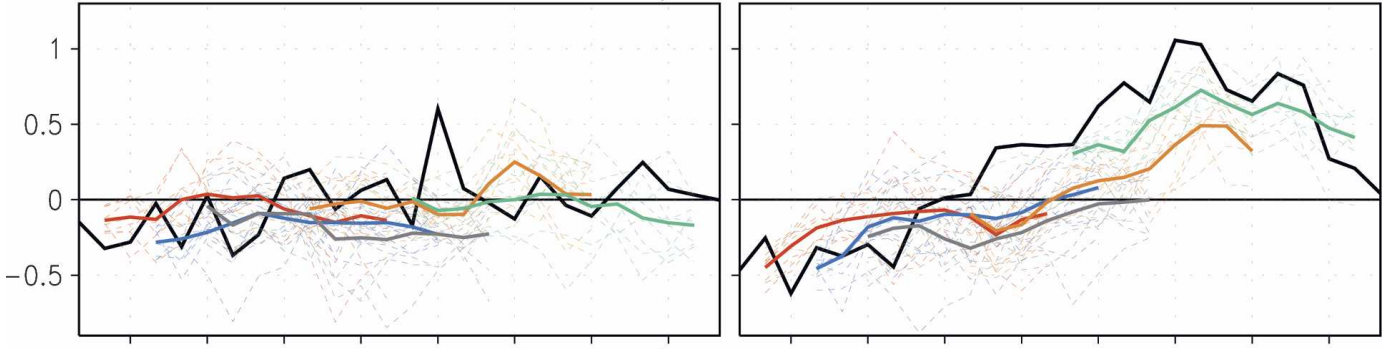

c) Nino3.4 SSTA

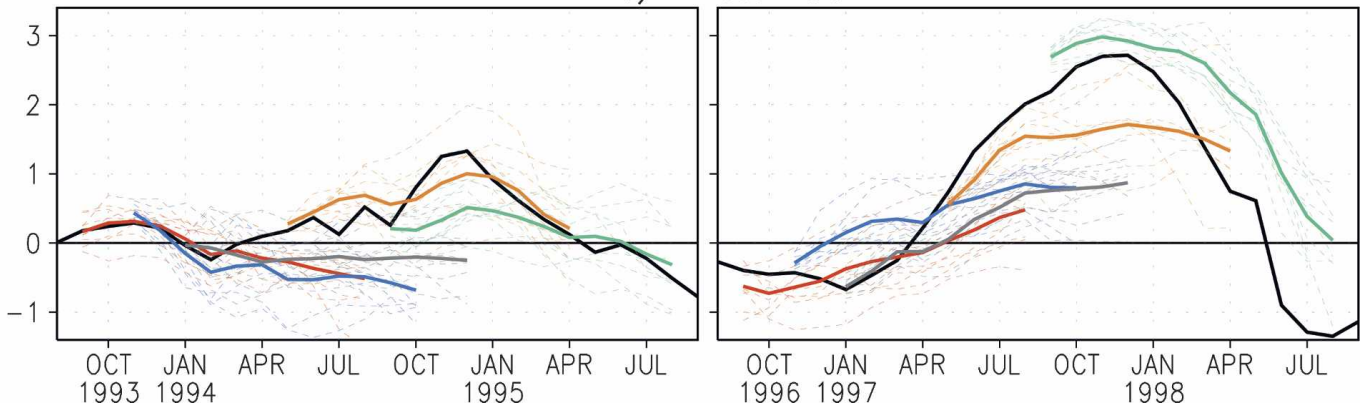

FIG. 4. (left) Predictions of the monthly (a) EIO, (b) WIO, and (c) Niño-3.4 ( $\left.5^{\circ} \mathrm{S}-5^{\circ} \mathrm{N}, 170^{\circ}-120^{\circ} \mathrm{W}\right)$ SST anomalies during the 1994 IOD event. The forecasts are initiated from 1 Sep and 1 Nov 1993, and 1 Jan, 1 May, and 1 Sep 1994 (red, blue, gray, yellow, and green lines), respectively. Same as in (left), but for the predictions of the 1997 case. The thick solid black and colored curves denote the NCEP monthly analysis and nine-member ensemble mean forecasts, respectively. The dashed lines show each member forecast. Results are based on unfiltered data.

in the 1997 fall (see Fig. 4a). The warm ISO event is related to an intraseasonal downwelling Kelvin wave generated by the surface westerly anomalies in the central equatorial Indian Ocean in the 1997 spring (e.g., Chambers et al. 1999; Rao and Yamagata 2004). Another shortcoming is that the model could not predict the strong cold signals in the eastern pole even starting from the summer and early fall of 1997 after the demise of the warm ISO event there. This is related to the errors in model initial subsurface conditions as shown later. We note that forecast systems with ocean data assimilation give better predictions for the 1997 event (see Wajsowicz 2004, 2005). In the western Indian Ocean, the strong warm SST anomalies in 1997 are predicted reasonably well, associated with the wellpredicted strong El Niño condition in the Pacific except that the predicted onsets are slightly delayed (Figs.
$4 b, c)$. In contrast, weak and high-frequency signals appeared in the western pole during 1994; their predictability is rather low. The model shows limited predictability for the 1994 mild El Niño-like event in the Pacific (see also Luo et al. 2005b, 2006, manuscript submitted to J. Climate).

\section{2) ERror ANALYSIS}

To understand the different performances of the model in predicting the eastern pole SST anomalies between the two IOD events, we have checked the initial thermocline conditions in 1994 and 1997 (Fig. 5). The oceanic thermocline along the west coast of Sumatra shallows quickly in the 1994 spring associated with strong anomalous southeasterly winds there (Figs. $5 \mathrm{a}, \mathrm{c})$. The $20^{\circ} \mathrm{C}$ isotherm is raised to about $10 \mathrm{~m}$ above the normal position during the 1994 spring-fall. The 

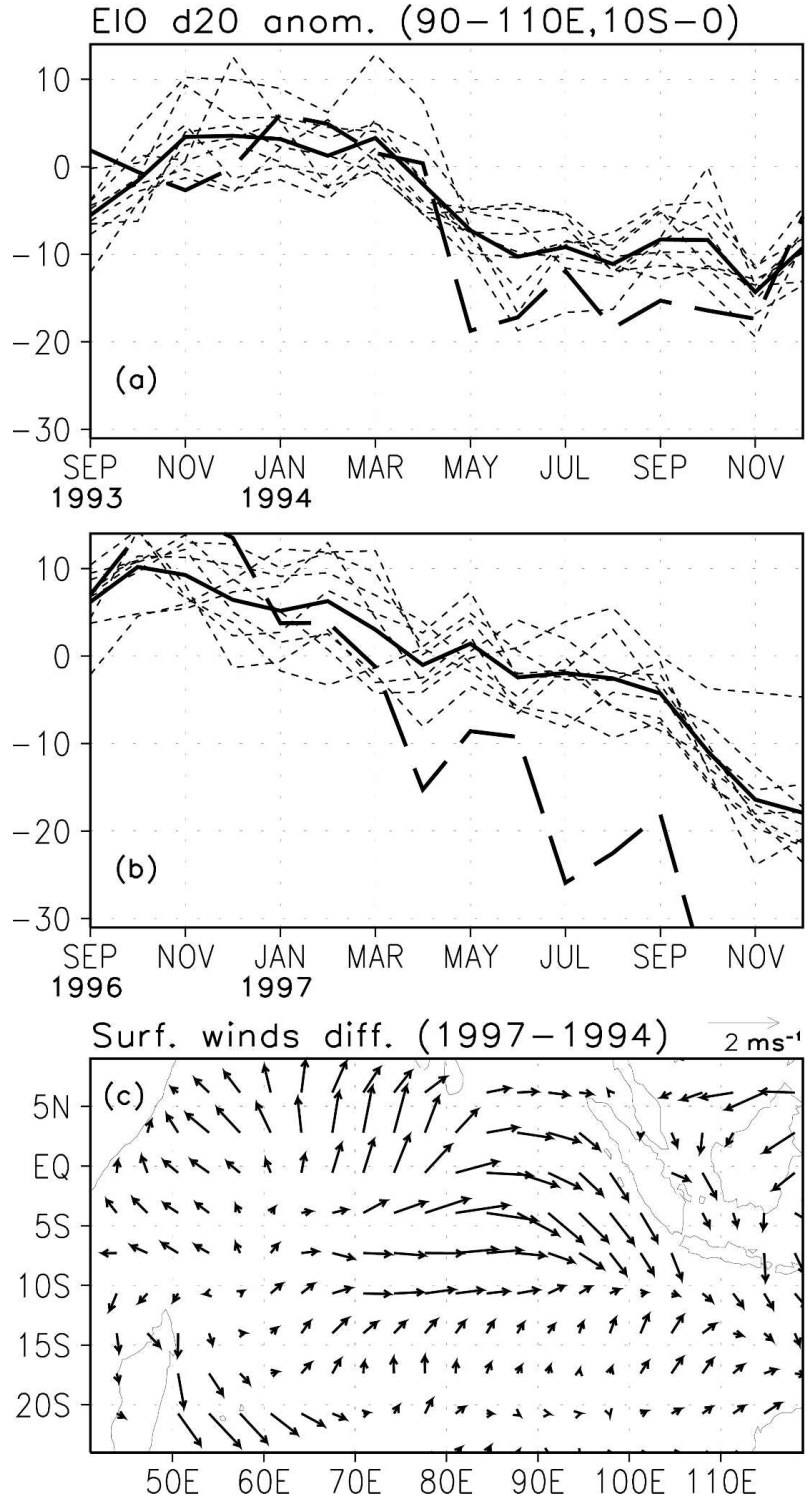

FIG. 5. EIO $20^{\circ} \mathrm{C}$ isotherm depth anomalies in (a) 1994 and (b) 1997 produced by the coupled SST nudging scheme for individual members (short-dashed lines) and the ensemble mean (thick solid lines). SODA reanalysis (thick dashed lines) is also shown for comparison. (c) Model surface wind differences between MarchSeptember 1997 and March-September 1994.

model also produces anomalous southeasterly winds in the eastern region during 1997 but the wind strength is much weaker (Fig. 5c). ${ }^{3}$ Therefore, the thermocline in the eastern pole in 1997 has not risen sufficiently enough to provide favorable initial conditions for the development of strong cold SST anomalies there (Fig. 5b). The thermocline depth anomalies during the 1997

\footnotetext{
${ }^{3}$ We note that the southeasterly wind anomaly near the west coast of Sumatra in 1997 is comparable to that in 1994 according to the NCEP-NCAR reanalysis.
}

spring-fall are much smaller than those produced by the Simple Ocean Data Assimilation (SODA; Carton et al. 2000). This suggests that the suitable assimilation of the subsurface information could improve the IOD forecasts. Besides, the performance of the atmospheric GCM in simulating the surface winds in the Indian Ocean needs to be improved.

\section{3) Spatial SST and RAinfall ANOMALIES}

The dipole structure of the SST anomalies (strong colder SSTs in the eastern and weak warmer ones in the western tropical Indian Ocean) in the 1994 boreal fall is successfully predicted from 1 June 1994 (Figs. 6a,b). The cold SST anomalies (and hence drought), however, extend too far west to the western equatorial Indian Ocean; this represents a common model deficiency in simulating the Indian Ocean climate (e.g., Gualdi et al. 2003; Yamagata et al. 2004; Wajsowicz 2004; Cai et al. 2005). Such a bias is related to a poor simulation of the east-west-tilted thermocline in the equatorial Indian Ocean associated with too weak mean surface westerly winds in the model (see Fig. 1). The El Niño-like warming in the central equatorial Pacific in 1994 is well predicted but with weakened magnitudes. The model realistically predicts the drought in the eastern Indian Ocean, Indonesia, and Australia, and the floods in the western Indian Ocean, south India, and eastern Africa (Figs. 6f,g). The drought along the eastern coast of Asia from the Indochina Peninsula-Philippines to western Japan is predicted. Rainfall anomalies in the Pacific associated with the El Niño-like condition are predicted. Initiated from the 1994 spring, the strong cold SST anomalies in the east and the dipole structure of rainfall anomalies in the Indian Ocean are also predicted realistically (Figs. 6c,h). The similar features can also be seen in the predictions from the 1993/94 winter (Figs. 6d,e,i,j). The predicted cold SST anomalies near the west coast of Sumatra at the two long-lead times, however, are much weaker than the observations. Besides, the model gives a false alarm of a weak cooling in the western Indian Ocean; this is related to the wrongly predicted La Niña condition in the Pacific (Figs. 6d,e).

The 1997 positive IOD event can be predicted from 1 June 1997 but with very weakened magnitudes (Figs. $7 \mathrm{a}, \mathrm{b}, \mathrm{f}, \mathrm{g})$. Nevertheless, the dipole pattern of rainfall anomalies in the Indian Ocean and the drought in Australia and eastern Asia are predicted reasonably well. The model shows a high predictability of the 1997/98 El Niño event (Figs. 7c-e). Its related rainfall anomalies in the Pacific (i.e., floods in the central and eastern equatorial Pacific and drought in the intertropical convergence zone and South Pacific convergence zone) can be 
a) Observed SSTA; SON1994

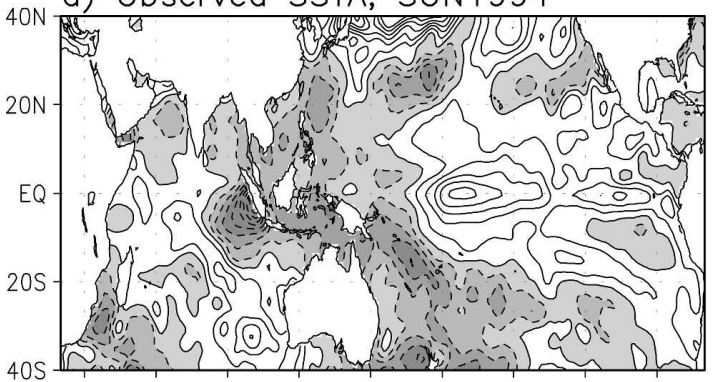

b) Predicted from 1 Jun 1994

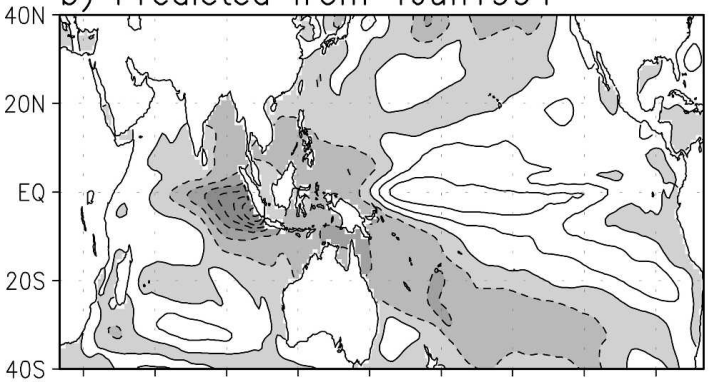

c) Predicted from 1Apr 1994
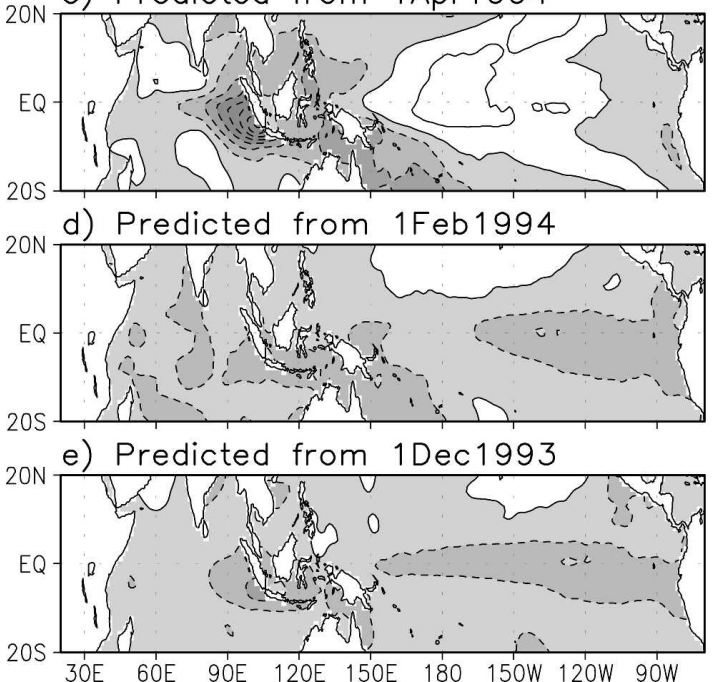

f) CMAP precip. anom.; SON1994

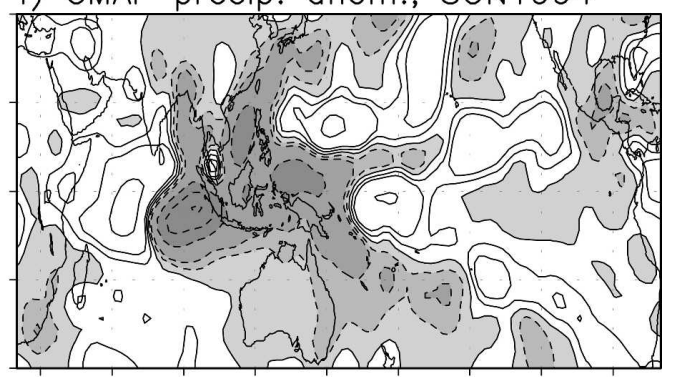

g) Predicted from 1 Jun 1994

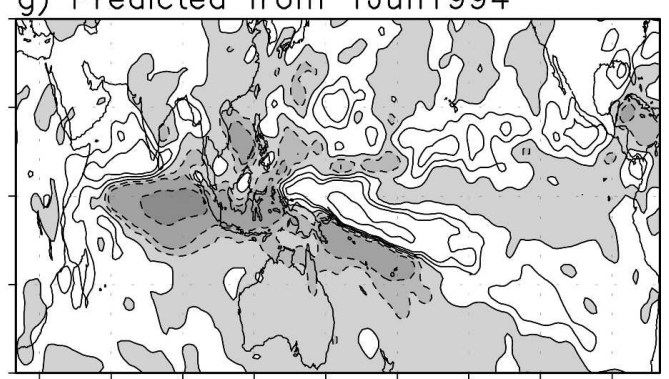

h) Predicted from $1 \mathrm{Apr} 1994$

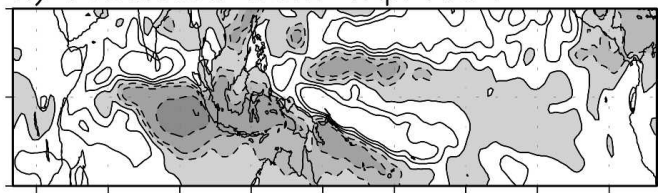

i) Predicted from $1 \mathrm{Feb} 1994$

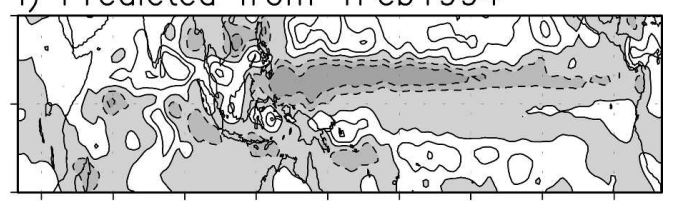

j) Predicted from 1Dec1993

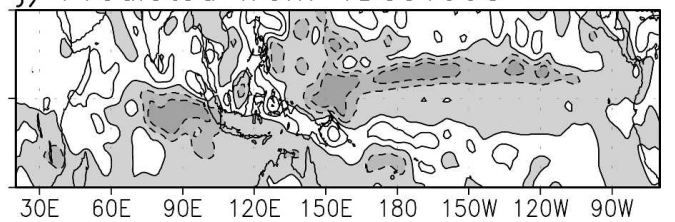

FIG. 6. (a)-(e) SST anomalies averaged in September-November 1994 based on the observations and model 9-member ensemble mean predictions from 1 Jun, 1 Apr, and 1 Feb 1994, and 1 Dec 1993, respectively. Contour interval (CI) is $0.3^{\circ} \mathrm{C}$ and regions with negative values are shaded. (f)-(j) Same as in (a)-(e), but for the precipitation anomalies (contour: $0, \pm 0.5, \pm 1, \pm 3, \pm 5 \mathrm{~mm} \mathrm{day}^{-1}$..). Results have been spatially smoothed with nearby 9 points for clarity.

predicted from as early as the 1996/97 winter (Figs. $7 \mathrm{~g}-\mathrm{j}$ ). Correspondingly, warmer SSTs and more rainfall in the western equatorial Indian Ocean are predicted from the 1996/97 winter and 1997 spring, though the predicted magnitudes are much weaker than the observations. In contrast, the model predicts weak cold and even warm SST anomalies along the west coast of Sumatra at these lead times (Figs. 7c-e). This is due to the fact that anomalous southeasterly winds in the model are too weak there and hence cannot raise the oceanic thermocline to above the normal level (see Fig. 5).

\section{Experimental real-time forecasts}

\section{a. Fall and winter 2005}

Our experimental real-time forecasts with 18 ensemble members were started in early 2005 . To generate 18 initial conditions, we have also used the OI daily SST products merged from two microwave satellite retrievals-the Tropical Rainfall Measuring Mission (TRMM) Microwave Imager (TMI) and the Advanced Microwave Scanning Radiometer (AMSR)-Earth Observing System (AMSR-E) - available online from 


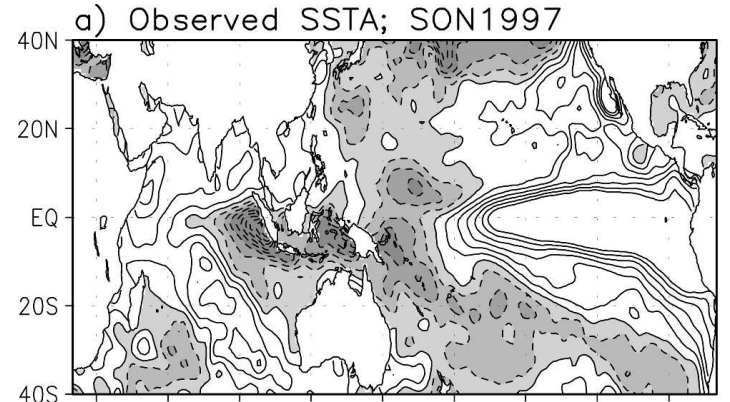

f) CMAP precip. anom.; SON1997
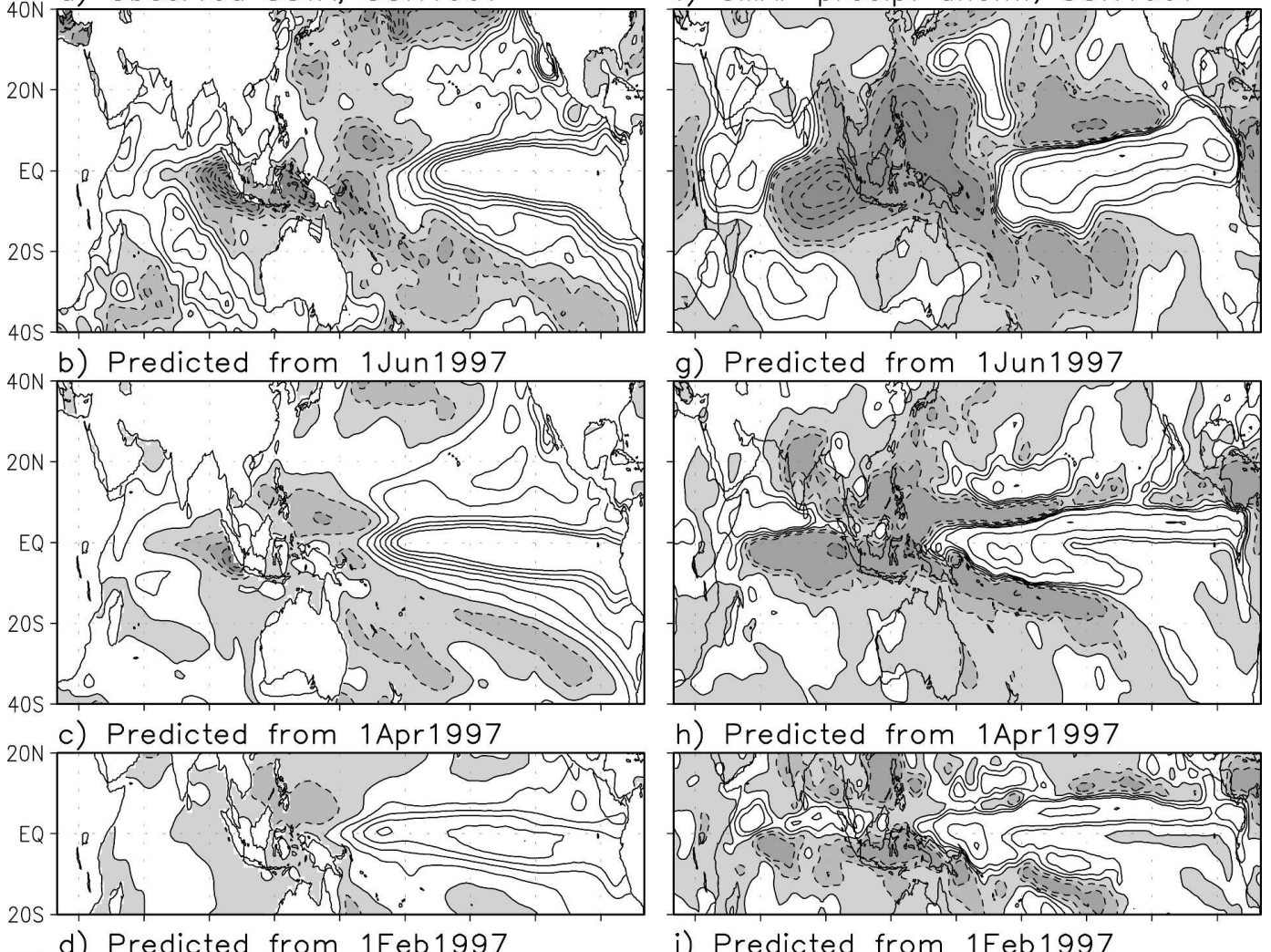

h) Predicted from 1 Apr1997
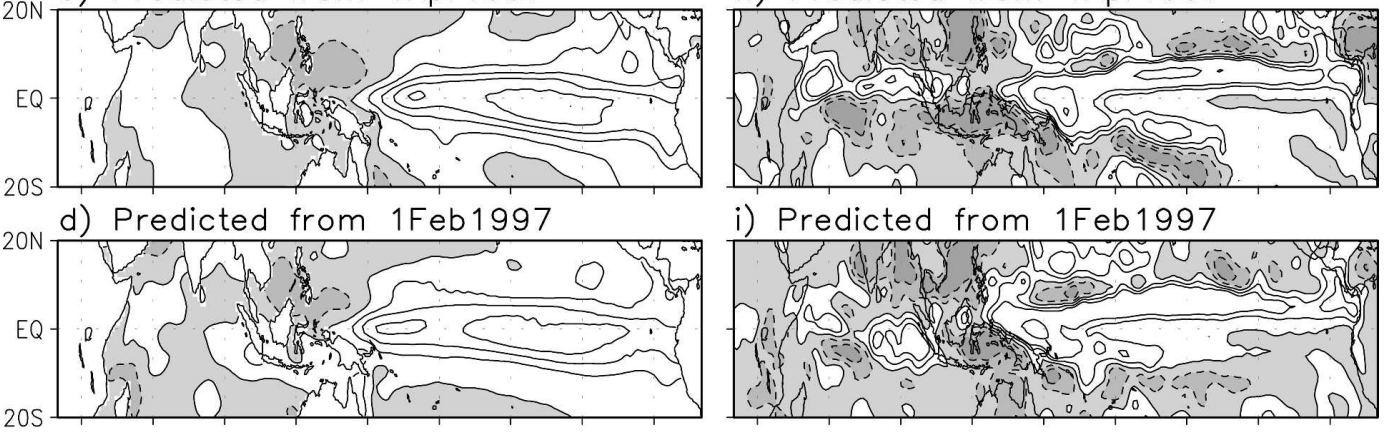

i) Predicted from $1 \mathrm{Feb} 1997$
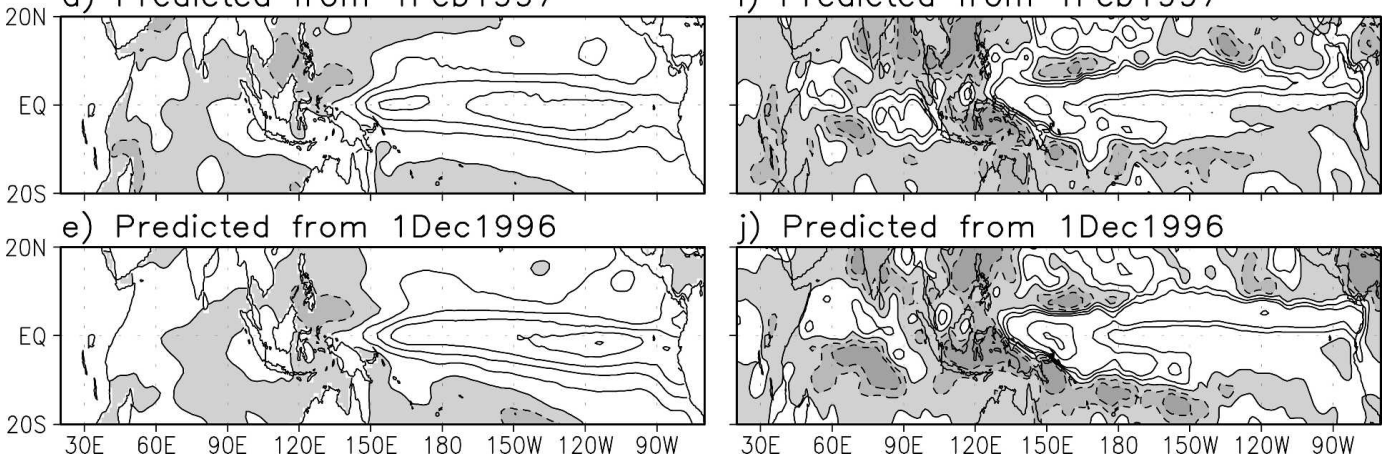

FIG. 7. Same as in Fig. 6, but for the period of September-November 1997.

June 2002 (see http://www.ssmi.com/). One advantage over the infrared satellites is that the microwave ones are capable of measuring global through-cloud SSTs. We note that large ensemble members are important for improving the seasonal climate forecasts in the Indian Ocean because of active ISOs there.

Model forecasts initiated from 1 April to 1 August 2005 showed a weak negative IOD with warm SST anomalies appearing in the eastern Indian Ocean in September-November 2005 and a La Niña condition in the Pacific in the 2005/06 winter (Fig. 8). Ensemble spreads among 18 members are quite large as seen from the forecasts initiated from 1 April and 1 June 2005; probabilities of both negative and positive IOD events in September-November 2005 coexist (Fig. 8a). This suggests limited predictability for weak IOD events. Probabilistic forecasts based on large ensemble members could provide a reliable solution for this case. We note that the ensemble mean forecast tends to have the maximum likelihood of occurrence if the distribution of ensemble members is not highly irregular (e.g., Barnston et al. 2005). All ensemble mean forecasts initiated at 1-month intervals since 1 April 2005 showed a weak negative IOD in the 2005 fall; they are consistent with those initiated from 1 August 2005. The latter have much smaller ensemble spreads. 

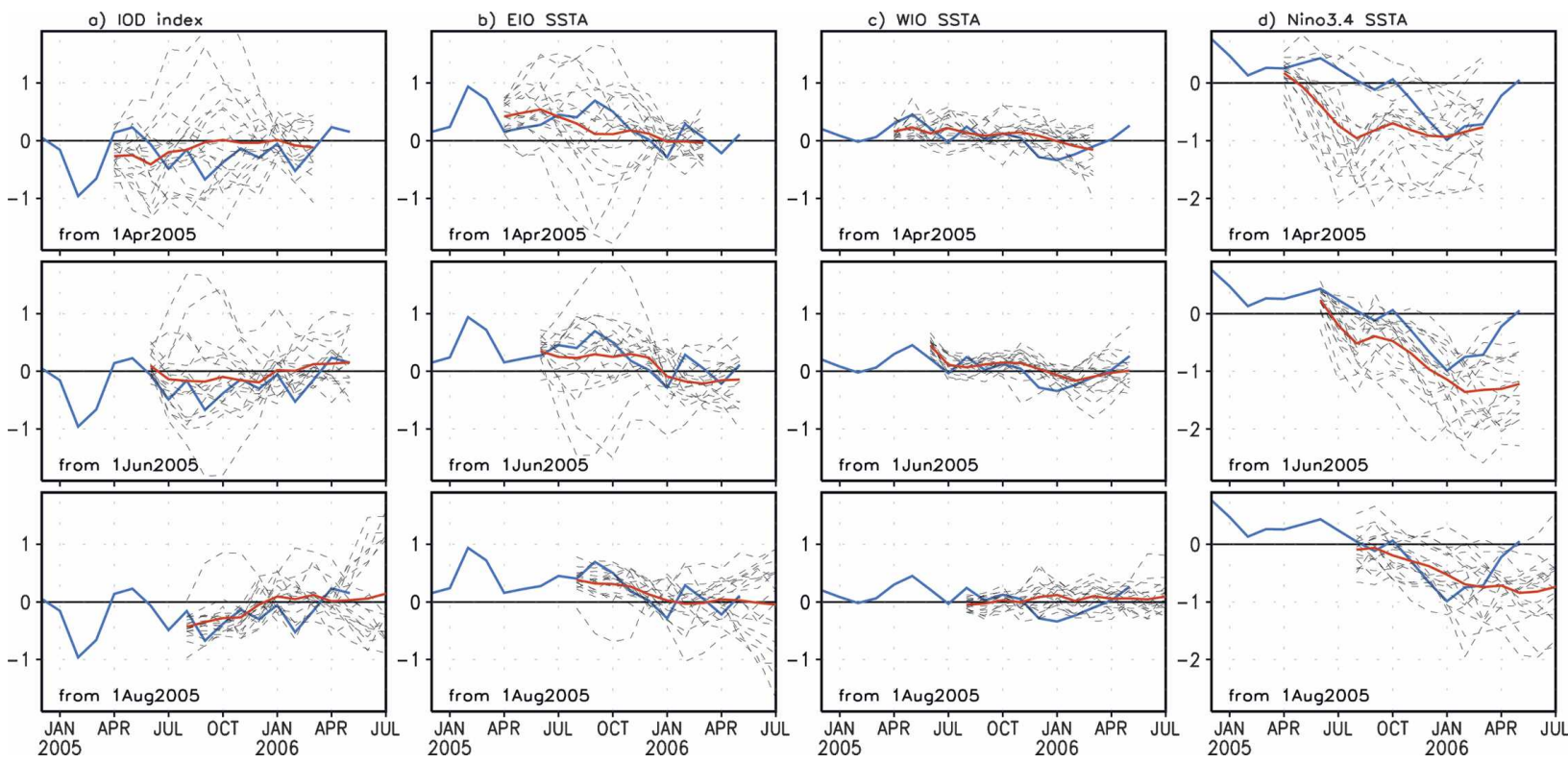

FIG. 8. Forecasts of the monthly (a) IOD index, (b) EIO, (c) WIO, and (d) Niño-3.4 SST anomalies initiated from 1 Apr, 1 Jun, and 1 Aug 2005, respectively. The blue curves denote NCEP monthly analysis and the red curves the 18 -member ensemble mean forecasts for 12 target months.

The weak negative IOD in 2005 fall is primarily caused by the mild warm SST anomalies in the eastern pole; signals in the western pole are very weak (Figs. $8 \mathrm{~b}, \mathrm{c})$. Correspondingly, predictions for the eastern pole SST anomalies initiated from 1 April and 1 June 2005 also show large ensemble spreads (Fig. 8b). Twelve (13) out of the total 18 members predicted the warmer SSTs there in fall 2005 from 1 April (June) 2005. Success of those members is related to a deeper thermocline condition near the west coast of Sumatra in the model (Fig. 9). This again suggests the importance of assimilating subsurface observations in the prediction system. Realistic subsurface information may help to reduce the large ensemble spreads and improve the predictability. Despite the nonstrong warming in the eastern pole, significant floods appeared in fall 2005 because of the warm mean SST state there (Figs. 10a,c). A clear dipole structure of rainfall anomalies associated with the negative IOD in fall 2005 was observed. These are predicted reasonably well by the model initiated from 1 June 2005 despite the deficiency that the predicted warm SST and positive rainfall anomalies extend too far westward (Figs. 10b,d). In the tropical Pacific, a La Niña condition started to develop in fall 2005; significant cold SST anomalies appeared near the west coast of South America (Fig. 10a). This is well predicted by the model except that the predicted cold signals (and hence drought) extend far too west to the western and central equatorial Pacific (Figs. 10b,d).

We note that a realistic long-range forecast of the $\mathrm{La}$
Niña event developed in late 2005 is difficult owing to active ISOs in the equatorial Pacific. Failure in capturing the strong warm oceanic Kelvin wave during February-May 2005 (because of no assimilation of the subsurface information) leads to the false prediction of an earlier onset of La Niña (see Fig. 8d). Initial cold sub-
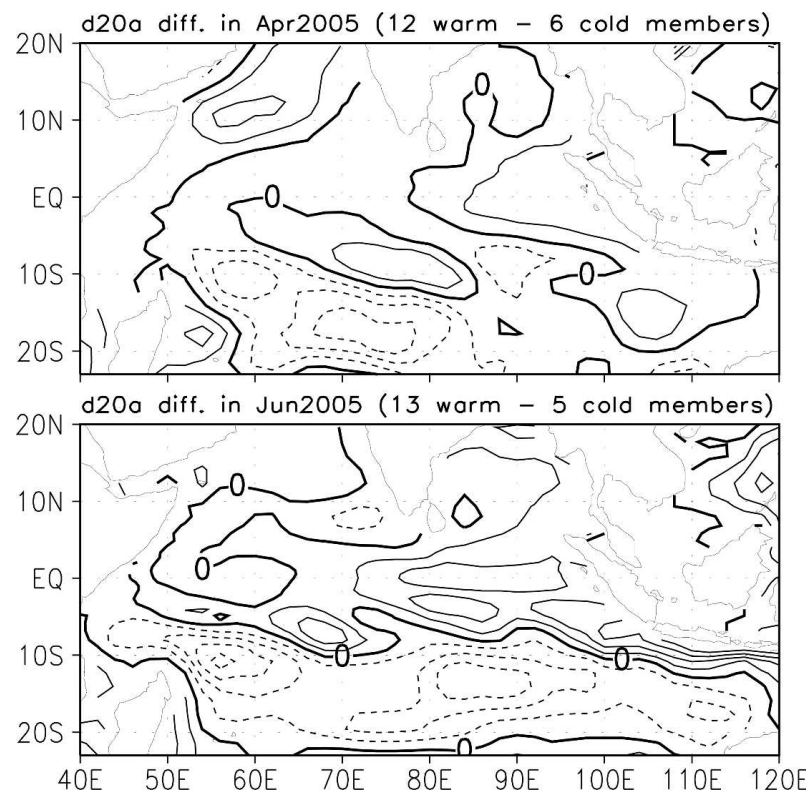

FIG. 9. Differences of the model $20^{\circ} \mathrm{C}$ isotherm depth anomalies $(\mathrm{CI}=3 \mathrm{~m})$ in April and June 2005. These are based on two groups of members that predicted warmer and colder SSTs in the eastern pole in the 2005 fall. 
a) Observed SSTA; SON2005

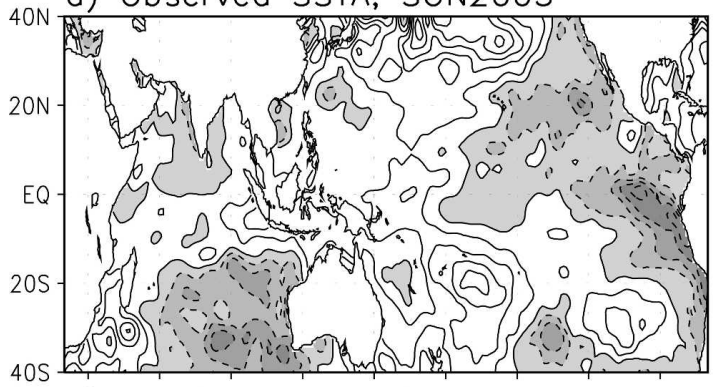

b) Predicted from $1 \mathrm{Jun} 2005$

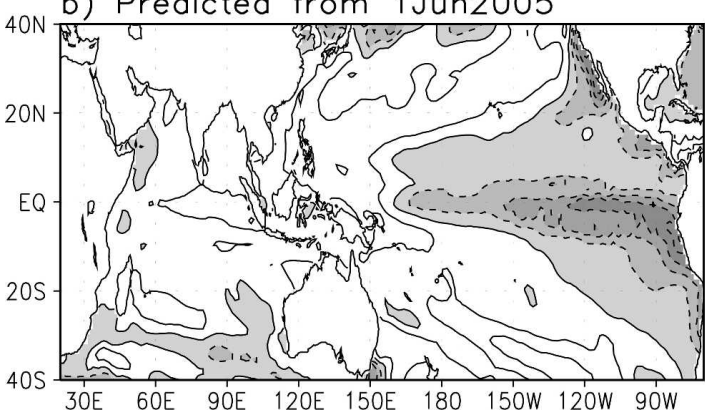

c) CMAP precip. anom.; SON2005

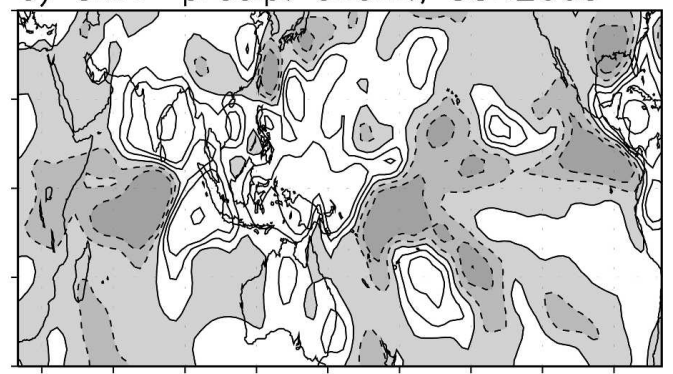

d) Predicted from 1 Jun2005

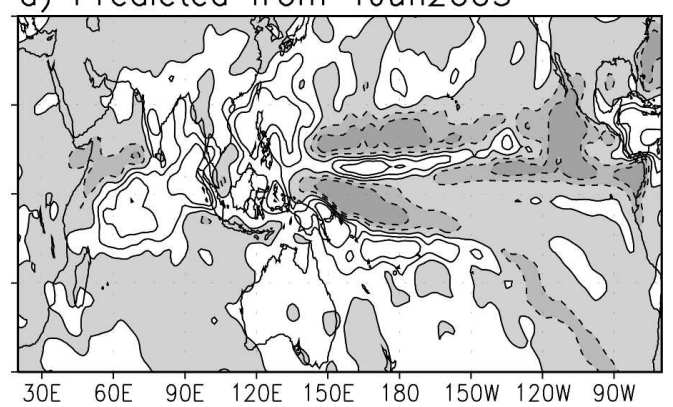

FIG. 10. Same as in Fig. 6, but for the 2005 fall SST and precipitation anomalies based on the observations and model predictions from 1 Jun 2005.

surface signals were observed in the eastern Pacific in early August of 2005 and a typical La Niña condition developed in the 2005/06 winter (see online at http:// www.cpc.ncep.noaa.gov/products/precip/CWlink/MJO/ enso.shtml). The La Niña condition in the 2005/06 winter is successfully predicted from as early as 1 March 2005 by the forecast system (see Figs. 13a,e). However, the rapid decay of the La Niña signal in the 2006 spring is not predicted. Predicting ENSO onset and decay seems to be rather difficult, as found in many other forecast systems (e.g., Landsea and Knaff 2000).

\section{b. Summer and fall 2006}

Figure 11a shows the Indian Ocean subsurface conditions averaged from November 2005 to February 2006 as produced by the coupled SST nudging scheme. Substantial cold subsurface signals have appeared in the southwestern Indian Ocean and extended to the western equatorial region. Such a situation is similar to that in 1993/94 (Fig. 11b) and may favor the development of a positive IOD in the following summer and fall (e.g., Rao et al. 2002). Besides, newly available observations in the equatorial Pacific up to June 2006 showed that the La Niña signal has finished and warm subsurface signals have appeared in the east (see http://www.cpc. ncep.noaa.gov/products/precip/CWlink/MJO/enso. shtml). A warmer condition in the equatorial Pacific might favor the development of a positive IOD in 2006.

Indeed, the model forecasts initiated since 1 Novem- ber 2005 consistently show that a positive IOD would appear in the 2006 summer and fall (Fig. 12a). Strong cold SST anomalies would occur in the eastern pole with weak warm anomalies appearing in the western Indian Ocean (Figs. 12b,c). The latter is consistent with the model ENSO forecasts (Fig. 12d). The results show that the La Niña condition in the equatorial Pacific would end in summer 2006 and a weak El Niño might happen if westerly wind bursts in the western Pacific, which have been active since 2002, also appeared in 2006. We note that the rapid decay of the La Niña signal in the 2006 spring is not well predicted even at short lead times (see Fig. 12d).

The consensus forecasts initiated from 1 December 2005 to 1 March 2006 show that cold SST anomalies would still persist in the central and eastern equatorial Pacific in spring 2006 (Fig. 13b). Correspondingly, warm anomalies would appear in the central North and South Pacific associated with the atmospheric teleconnections of La Niña. In the tropical Indian Ocean, basinwide cold SST anomalies would occur in the 2006 spring in accord with the La Niña condition. These are similar to the newly available observations except that the observed La Niña condition weakened rather quickly and weak warm SST anomalies appeared in the equatorial Indian Ocean (Fig. 13f). A clear positive IOD pattern would develop in the following summer and peak in the 2006 fall with strong cold SST anomalies larger than $-0.5^{\circ} \mathrm{C}$ appearing near the west coast of Sumatra (Figs. 13c,d). The predicted situation in the 

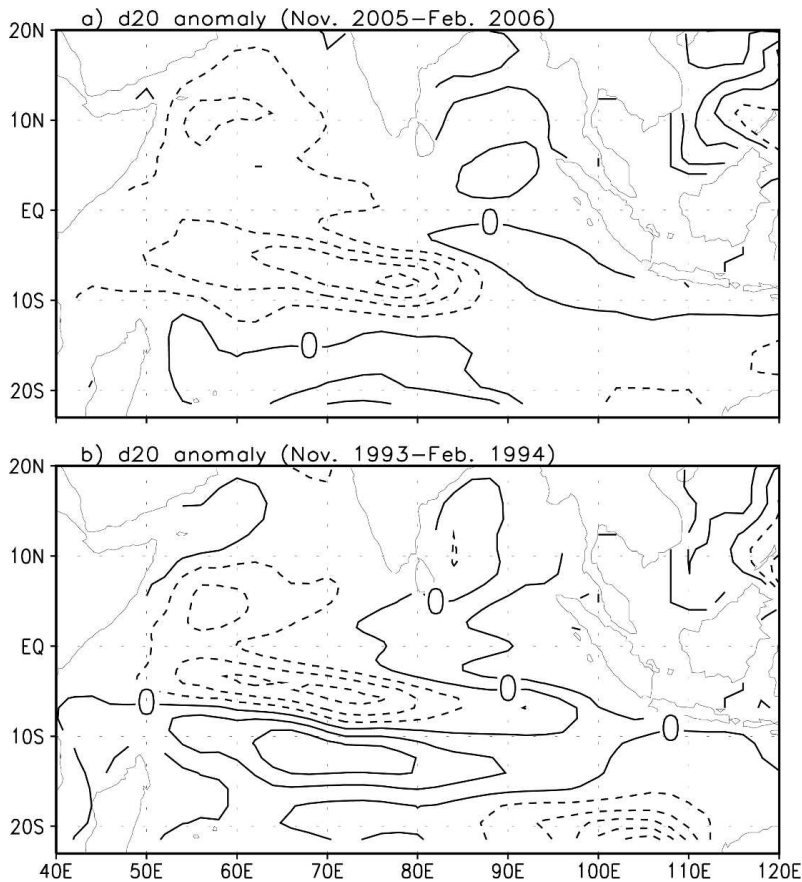

FIG. 11. The $20^{\circ} \mathrm{C}$ isotherm depth anomalies $(\mathrm{CI}=5 \mathrm{~m})$ averaged from (a) November 2005 to February 2006 and (b) November 1993 to February 1994. These are produced by the coupled SST nudging scheme based on the NCEP SST observations.

tropical Indo-Pacific sector in the 2006 summer and fall seems to be similar to that in 1994.

\section{Summary and discussion}

In this study, we have investigated the climate predictability in the tropical Indian Ocean based on 9-member ensemble hindcasts over the past 2 decades. The results show skillful scores of the IOD index predictions up to a 3-4-month lead with an intrinsic winter prediction barrier. In the western Indian Ocean, several warm SST anomalies (during 1983, 1987, 1991, 1997/98, and 2003) and cold anomalies (1985, 1989, 1996, and 1999) can be predicted reasonably well up to a 9-12month lead. This is associated with the large influences of ENSO, which is highly predictable. In contrast, it is rather challenging to predict the SST anomaly in the eastern Indian Ocean. The model, however, can skillfully predict the signal there up to about 2 seasons ahead. Considering the complicated and delicate physical processes governing the IOD and sparse subsurface observations in the Indian Ocean, it is encouraging that current state-of-the-art ocean-atmosphere coupled models are capable of predicting the extreme IOD episode in 1994 at a 2-3-season lead. It is worth noting that the model fails to predict the strong cold SST anomalies in the eastern pole in the 1997 fall despite the wellpredicted strong warming in the western pole associ- ated with the unprecedented El Niño influence. This is mainly due to the errors in the initial subsurface conditions associated with too weak southeasterly winds along the west coast of Sumatra in the model.

In the presence of chaotic and energetic ISOs in the Indian Ocean, substantially increasing ensemble members could improve the long-range forecasts of IOD. Large ensembles are needed to make reliable probabilistic forecasts. This is a future work. It is encouraging that the real-time forecasts with 18 members realistically predicted the weak negative IOD in the 2005 fall and La Niña condition in the 2005/06 winter up to 2 or 3 seasons ahead. Model forecasts initiated since 1 November 2005 show that a positive IOD event would occur in the 2006 summer and fall accompanied by a possible weak El Niño condition in the equatorial $\mathrm{Pa}$ cific. We note that such long-lead predictions of IOD, however, might be reliable only in certain circumstances such as 1994. Model forecasts should be kept updated on a monthly basis and validated with observations. They are available online (see http://www. jamstec.go.jp/frcgc/research/d1/iod/index.html).

Besides, large efforts are required to improve the performance of both atmospheric and oceanic GCMs in simulating the tropical Indian Ocean climate. The flat zonal thermocline in the equatorial Indian Ocean associated with too weak westerly winds in the model may affect the probability density function of IOD predictions, favoring the occurrence of strong events. The Indonesia Throughflow that carries the water from the western Pacific to the eastern Indian Ocean must also be resolved in a more precise way in next-generation coupled models. Errors in the initial subsurface conditions in the tropical Indian Ocean may largely affect the IOD predictions in some circumstances. Our results suggest that realistic subsurface information in the eastern Indian Ocean, particularly along the west coast of Sumatra, could improve the IOD predictions. Besides, strong subsurface signals in the southwestern tropical Indian Ocean at $5^{\circ}-12^{\circ} \mathrm{S}$ can contribute to the preconditioning of IOD events. Ocean observations with sufficient coverage in this area may help to improve the long-range lead forecasts of IOD. Current international the World Climate Research Programme/Climate Variability and Predictability (WCRP/CLIVAR) and Earth Observing System/Global Earth Observation System of Systems/Global Ocean Observing System (EOS/ GEOSS/GOOS) to establish a long-term monitoring system in the tropical Indian Ocean [similar to the counterpart Tropical Atmosphere Ocean/Triangle Trans-Ocean Buoy Network (TAO/TRITON) in the Pacific] will increase the forecast skills of IOD by providing better initial conditions. 

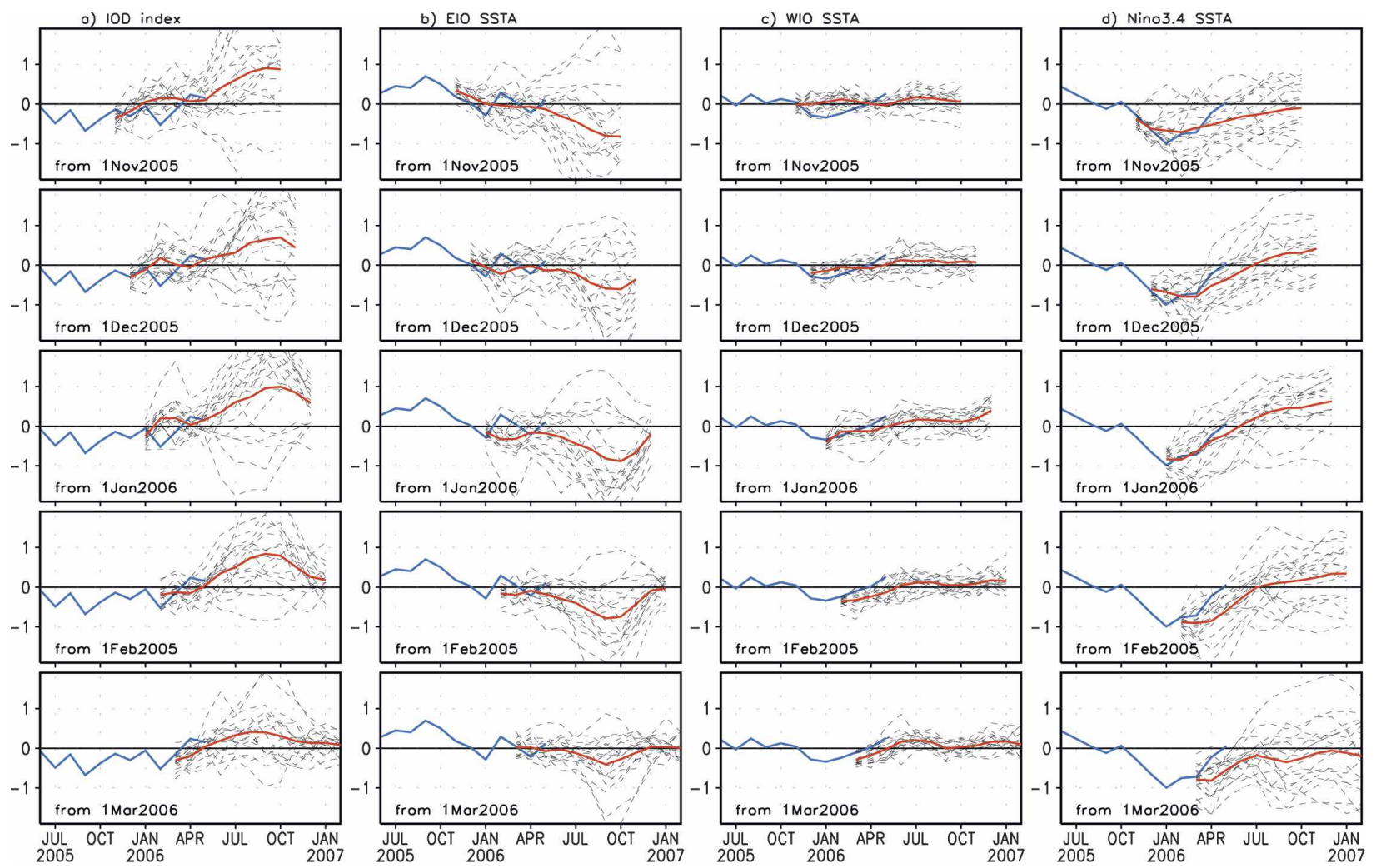

FIG. 12. Same as in Fig. 8, but for the model forecasts initiated from 1 Nov and 1 Dec 2005, and 1 Jan, 1 Feb, and 1 Mar 2006, respectively. We note that recent predictions from 1 Apr, 1 May, and 1 Jun 2006 also show a positive IOD in the 2006 summer and fall (see online at http://www.jamstec.go.jp/frcgc/research/d1/iod/index.html).
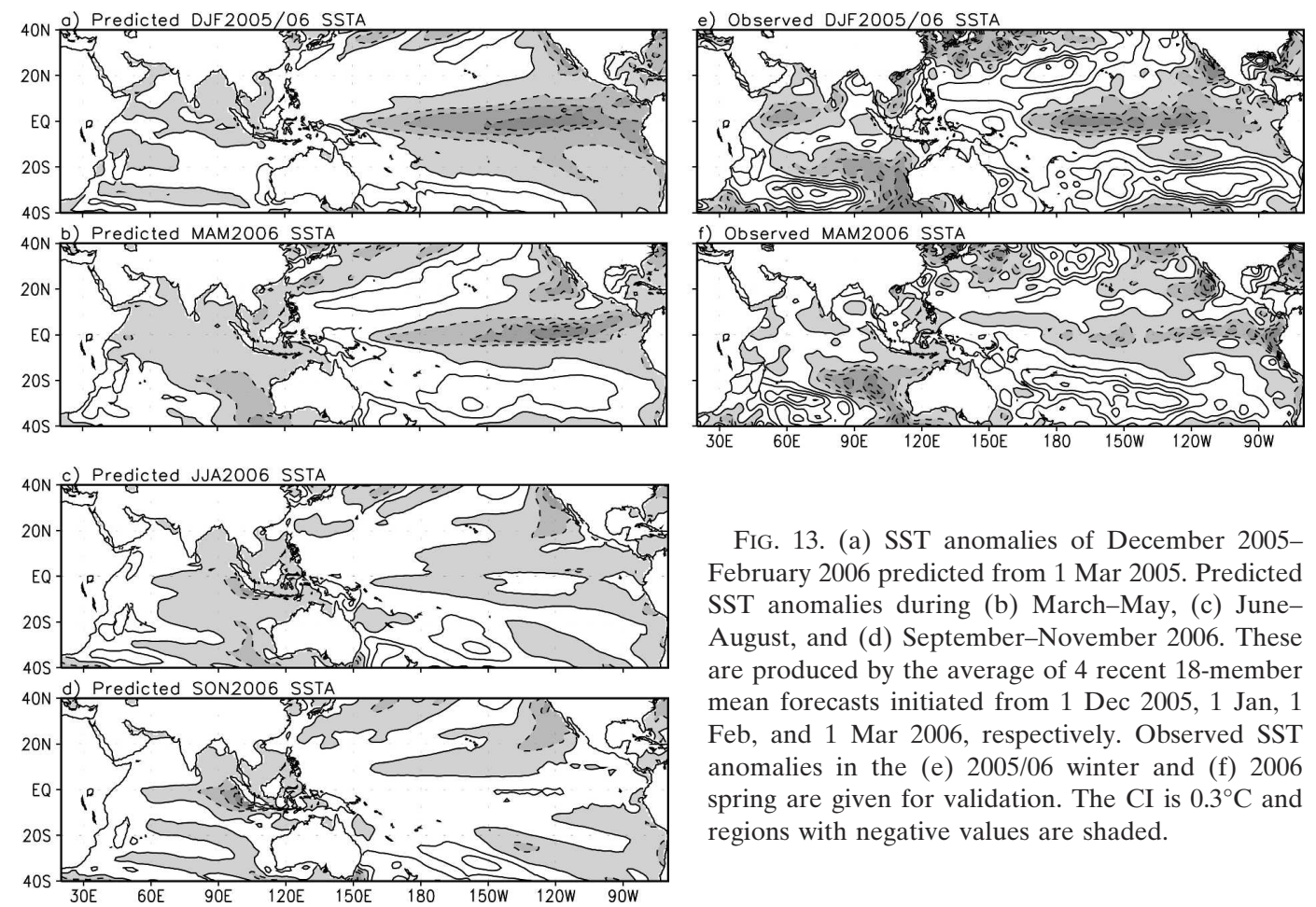

FIG. 13. (a) SST anomalies of December 2005February 2006 predicted from 1 Mar 2005. Predicted SST anomalies during (b) March-May, (c) JuneAugust, and (d) September-November 2006. These are produced by the average of 4 recent 18 -member mean forecasts initiated from 1 Dec 2005, 1 Jan, 1 Feb, and 1 Mar 2006, respectively. Observed SST anomalies in the (e) 2005/06 winter and (f) 2006 spring are given for validation. The $\mathrm{CI}$ is $0.3^{\circ} \mathrm{C}$ and regions with negative values are shaded. 
Acknowledgments. The SINTEX-F model integrations were carried out on the Earth Simulator. The atmosphere model (ECHAM4) was provided by MPIMet (Hamburg), the ocean model (OPA) by LODYC (Paris), and the coupler (OASIS) by CERFACS (Toulouse). We thank Gary Meyers, Antonio Navarra, Stuart Godfrey, Michael McPhaden, Shang-Ping Xie, and Roxana Wajsowicz for helpful discussions and two anonymous reviewers for their valuable comments that helped improve the manuscript greatly.

\section{REFERENCES}

Ansell, T., C. J. C. Reason, and G. Meyers, 2000: Variability in the tropical southeast Indian Ocean and links with southeast Australian winter rainfall. Geophys. Res. Lett., 27, 3977-3980.

Barnston, A. G., A. Kumar, L. Goddard, and M. P. Hoerling, 2005: Improving seasonal prediction practices through attribution of climate variability. Bull. Amer. Meteor. Soc., 86, $59-72$.

Behera, S. K., and T. Yamagata, 2003: Influence of the Indian Ocean dipole on the Southern Oscillation. J. Meteor. Soc. Japan, 81, 169-177.

—_, R. Krishnan, and T. Yamagata, 1999: Unusual oceanatmosphere conditions in the tropical Indian Ocean during 1994. Geophys. Res. Lett., 26, 3001-3004.

_ - J.-J. Luo, S. Masson, P. Delecluse, S. Gualdi, A. Navarra, and T. Yamagata, 2005: Paramount impact of the Indian Ocean dipole on the East African short rains: A CGCM study. J. Climate, 18, 4514-4530.

Birkett, C., R. Murtugudde, and T. Allan, 1999: Indian Ocean climate event brings floods to East Africa's lakes and the Sudd Marsh. Geophys. Res. Lett., 26, 1031-1034.

Cai, W., H. H. Hendon, and G. Meyers, 2005: Indian Ocean dipole variability in the CSIRO Mark 3 coupled climate model. $J$. Climate, 18, 1449-1468.

Cane, M. A., S. E. Zebiak, and S. C. Dolan, 1986: Experimental forecasts of El Niño. Nature, 321, 827-832.

Carton, J. A., G. Chepurin, and X. Cao, 2000: A simple ocean data assimilation analysis of the global upper ocean 1950-1995. Part II: Results. J. Phys. Oceanogr., 30, 311-326.

Chambers, D. P., B. D. Tapley, and R. H. Stewart, 1999: Anomalous warming in the Indian Ocean coincident with El Niño. $J$. Geophys. Res., 104, 3035-3047.

Chen, D., S. E. Zebiak, A. J. Busalacchi, and M. A. Cane, 1995: An improved procedure for El Niño forecasting: Implications for predictability. Science, 269, 1699-1702.

Clark, C. O., P. J. Webster, and J. E. Cole, 2003: Interdecadal variability of the relationship between the Indian Ocean zonal mode and East African coastal rainfall anomalies. $J$. Climate, 16, 548-554.

Gualdi, S., E. Guilyardi, A. Navarra, S. Masina, and P. Delecluse, 2003: The interannual variability in the tropical Indian Ocean as simulated by a CGCM. Climate Dyn., 10, 567-582.

Han, W., W. T. Liu, and J. Lin, 2006: Impact of atmospheric submonthly oscillations on sea surface temperature of the tropical Indian Ocean. Geophys. Res. Lett., 33, L03609, doi:10.1029/2005GL025082.

Kirtman, B. P., J. Shukla, B. Huang, Z. Zhu, and E. K. Schneider, 1997: Multiseasonal predictions with a coupled tropical ocean-global atmosphere system. Mon. Wea. Rev., 125, 789-808.

Landsea, C. W., and J. A. Knaff, 2000: How much skill was there in forecasting the very strong 1997-98 El Niño? Bull. Amer. Meteor. Soc., 81, 2107-2119.

Li, T., B. Wang, C.-P. Chang, and Y. Zhang, 2003: A theory for the Indian Ocean dipole-zonal mode. J. Atmos. Sci., 60, 2119-2135.

Luo, J.-J., S. Masson, S. Behera, P. Delecluse, S. Gualdi, A. Navarra, and T. Yamagata, 2003: South Pacific origin of the decadal ENSO-like variation as simulated by a coupled GCM. Geophys. Res. Lett., 30, 2250, doi:10.1029/2003GL018649.

_,- , E. Roeckner, G. Madec, and T. Yamagata, 2005a: Reducing climatology bias in an ocean-atmosphere CGCM with improved coupling physics. J. Climate, 18, 2344-2360.

,-- S. Behera, S. Shingu, and T. Yamagata, 2005b: Seasonal climate predictability in a coupled OAGCM using a different approach for ensemble forecasts. J. Climate, 18, 4474-4497.

Masumoto, Y., H. Hase, Y. Kuroda, H. Matsuura, and K. Takeuchi, 2005: Intraseasonal variability in the upper layer currents observed in the eastern equatorial Indian Ocean. Geophys. Res. Lett., 32, L02607, doi:10.1029/2004GL021896.

Rao, S. A., and T. Yamagata, 2004: Abrupt termination of Indian Ocean dipole events in response to intraseasonal disturbances. Geophys. Res. Lett., 31, L19306, doi:10.1029/ 2004GL020842.

—, S. Behera, Y. Masumoto, and T. Yamagata, 2002: Interannual variability in the subsurface Indian Ocean with special emphasis on the Indian Ocean Dipole. Deep-Sea Res., 49, 1549-1572.

Saji, N. H., and T. Yamagata, 2003: Interference of teleconnection patterns generated from the tropical Indian and Pacific Oceans. Climate Res., 25, 151-169.

—, B. N. Goswami, P. N. Vinayachandran, and T. Yamagata, 1999: A dipole mode in the tropical Indian Ocean. Nature, 401, 360-363.

Stephens, C., J. I. Antonov, T. P. Boyer, M. E. Conkright, R. A. Locarnini, T. D. O'Brien, and H. E. Garcia, 2002: Temperature. Vol. 1, World Ocean Atlas 2001, NOAA Atlas NESDIS 49, $167 \mathrm{pp}$.

Stockdale, T. N., 1997: Coupled ocean-atmosphere forecasts in the presence of climate drift. Mon. Wea. Rev., 125, 809-818.

—, D. L. T. Anderson, J. O. S. Alves, and M. A. Balmaseda, 1998: Global seasonal rainfall forecasts using a coupled ocean-atmosphere model. Nature, 392, 370-373.

Tozuka, T., J.-J. Luo, S. Masson, and T. Yamagata, 2007: Decadal modulations of the Indian Ocean dipole in the SINTEX-F1 coupled GCM. J. Climate, in press.

Wajsowicz, R. C., 2004: Climate variability over the tropical Indian Ocean sector in the NSIPP seasonal forecast system. $J$. Climate, 17, 4783-4804.

_ 2005: Potential predictability of tropical Indian Ocean SST anomalies. Geophys. Res. Lett., 32, L24702, doi:10.1029/ 2005GL024169.

Webster, P. J., A. Moore, J. Loschnigg, and M. Leban, 1999: Coupled ocean-atmosphere dynamics in the Indian Ocean during 1997-98. Nature, 401, 356-360.

Yamagata, T., S. Behera, J.-J. Luo, S. Masson, M. Jury, and S. A. Rao, 2004: Coupled ocean-atmosphere variability in the tropical Indian Ocean. Earth's Climate: The OceanAtmosphere Interaction, Geophys. Monogr., Vol. 147, Amer. Geophys. Union, 189-212. 